\title{
O TESOURO DO LÉXICO PATRIMONIAL GALEGO E PORTUGUÉS E A SÚA CONTRIBUCIÓN Á LEXICOGRAFÍA E DIALECTOLOXÍA GALEGAS
}

Rosa Mouzo Villar

Instituto da Lingua Galega, Universidade de Santiago de Compostela doi:10.17075/tucmeg.2015.004 

CAStro, O. / M. LiÑEIRA (eds.) (2015): Trama e urda. Contribucións multidisciplinares desde os estudos galegos, Santiago de Compostela, Consello da Cultura Galega. doi:10.17075/tucmeg.2015.

\section{INTRODUCIÓN ${ }^{29}$}

O Tesouro do léxico patrimonial galego e portugués (de aquí en diante Tesouro) é un proxecto que se iniciou no ano 2007, coordinado desde o Instituto da Lingua Galega da Universidade de Santiago de Compostela pola profesora Rosario Álvarez Blanco, en colaboración con universidades de Brasil e Portugal. O seu principal obxectivo é integrar nun único banco de datos o léxico dialectal tradicional do galego, do portugués de Portugal e do portugués do Brasil. Deste xeito, o patrimonio inmaterial destes países, que a día de hoxe se encontra ameazado polo abandono do modo de vida tradicional, pode quedar rexistrado grazas a este proxecto internacional, que con isto permitirá preservar non só termos, senón tamén linguas e culturas.

Os principais destinatarios dunha ferramenta destas características son, obviamente, lingüistas das áreas galega e/ou portuguesa, pero é tamén de indubidable interese para estudosos das linguas románicas en xeral, investigadores do ámbito das ciencias sociais e outros especialistas que poderán sacar rendemento dos seus materiais. O material léxico que compón o Tesouro procede de fontes heteroxéneas, como poden ser traballos de campo, inquéritos de atlas lingüísticos, traballos académicos etc., descoñecidas para o público ou de difícil acceso para os investigadores. É o caso dos materiais galegos que aparecen recollidos no Tesouro e que trataremos ao longo deste artigo.

$\mathrm{Na}$ historia da lexicografía e dialectoloxía galegas téñense realizado multitude de estudos que pola súa escasa difusión ou polo obxecto co que foron elaborados non son moi coñecidos nin resultan de fácil acceso para os investigadores. Estes materiais están dispoñibles por primeira vez para a comunidade científica grazas ao Tesouro, a través do cal os usuarios teñen a posibilidade de realizaren consultas por lema ou variante para obteren diferente

\footnotetext{
${ }^{29}$ Este artigo inscríbese dentro do proxecto de investigación Tesouro do léxico patrimonial galego e portugués. Banco de datos electrónico (corpus galego) e cartografía automática (FFI2009-12110), financiado pola Secretaría de Estado de Investigación (Ministerio de Ciencia e Innovación). Gustaríame agradecerlles a Rosario Álvarez Blanco e a Ernesto González Seoane a axuda prestada ao longo da elaboración deste traballo. Grazas polos vosos comentarios, polas valiosas achegas e polos azos. Grazas tamén ás miñas compañeiras e compañeiros do ILG, con quen comparto traballo e moitas outras cousas
} 
CAStro, O. / M. LiÑEIRA (eds.) (2015): Trama e urda. Contribucións multidisciplinares desde os estudos galegos, Santiago de Compostela, Consello da Cultura Galega. doi:10.17075/tucmeg.2015.

información lexicográfica. Con todo, aínda que este proxecto está constituído fundamentalmente por formas léxicas, non faltan tampouco outras mostras da linguaxe oral como exemplos, refráns ou cancións, e tamén fotografías e debuxos que reproducen e preservan para a posterioridade construcións, ritos, instrumentos e todo tipo de obxectos pertencentes á cultura popular e tradicional. Ademais, a aplicación, á que se pode acceder en rede de forma libre e gratuíta $^{30}$ ofrece como novidade o feito de que esta información vai acompañada de mapas que dan conta da distribución xeográfica das formas e que é fundamental para obter información léxica das variedades dialectais. ${ }^{31}$ Aínda que o Tesouro é un proxecto internacional que reúne un amplo número de obras do dominio galego, portugués e brasileiro, neste estudo ímonos centrar no corpus galego para ver en que medida o Tesouro pode resultar un instrumento auxiliar moi valioso para a lexicografia e dialectoloxía galegas.

\section{OBRAS GALEGAS QUE COMPOÑEN O TESOURO. TIPOLOXÍA DAS FONTES}

$\mathrm{Na}$ actualidade (xullo de 2014), o Tesouro conta con 157.253 rexistros procedentes de 115 obras: 11 de Brasil, 55 de Portugal e 49 de Galicia, aínda que ao tratarse dun proxecto en construción, estas cifras irán incrementándose progresivamente ao longo dos próximos anos.

O corpus galego do Tesouro está composto, por unha banda, por materiais lexicógráficos con referencias xeográficas procedentes de distintas fontes, que tanto poden ser obras que foron publicadas, coma obras inéditas, que deste xeito estarán dispoñibles por primeira vez para a comunidade científica a través desta plataforma. Por outra banda, tamén teñen cabida neste proxecto desde os primeiros estudos de corte dialectolóxico, coma o de Hans-Karl Schneider sobre a Limia Baixa, teses de doutoramento que recollen a fala dun lugar, coma o Vocabulario del Valle de Suarna, e obras xeolingüísticas que cobren todo o territorio, coma o Atlas Lingüístico Galego $(A L G a)$.

Tanto os traballos lexicográficos coma os dialectais poden ser monografías (teses de doutoramento, teses de mestrado, outros traballos académicos e libros completos), pequenas contribucións (artigos de revistas e capítulos de libros) ou outro tipo de fontes que non responden exactamente a ningunha das descritas anteriormente (enquisas temáticas que se conservan

$30 \mathrm{O}$ Tesouro está dispoñible a través do enderezo http://ilg.usc.es/Tesouro/

31 Para coñecer máis polo miúdo o proxecto Tesouro do Léxico Patrimonial Galego e Portugués, véxase neste mesmo volume o artigo de Ernesto González. Véxase tamén Álvarez Blanco et alii (2009) e Álvarez Pérez \& Sousa Fernández (2013). 
CAStro, O. / M. LiÑEIRA (eds.) (2015): Trama e urda. Contribucións multidisciplinares desde os estudos galegos, Santiago de Compostela, Consello da Cultura Galega. doi:10.17075/tucmeg.2015.

no Instituto da Lingua Galega, publicacións locais e comarcais, recursos en páxinas web e bases de datos coma a do propio $A L G a$ ).

$\mathrm{Na}$ actualidade os artigos $(10,2 \%)$, as páxinas web $(8,2 \%)$, outros traballos académicos $(6,1 \%)$, os libros $(4,1 \%)$, as teses de doutoramento $(2,05 \%)$ e os capítulos de libros $(2,05 \%)$ son os que ocupan un lugar menor no Tesouro, mentres que os materiais máis abundantes na base de datos son, sobre todo, memorias de licenciatura $(67,3 \%)$, que poden presentarse en forma de glosario ou de obras redactadas. Neste último tipo de obras procédese a extraer o contexto lingüístico relacionado con cada palabra para que a presentación da información na aplicación sexa para todos os termos igual, con independencia da fonte de procedencia. Ademais da información lexicográfica, algunhas obras achegan información complementaria, sempre de moita utilidade e interese, coma as imaxes que acompañan determinadas voces, os textos que detallan como é a cultura do lugar, contos, refráns etc. (véxanse Figuras 1 e 2).

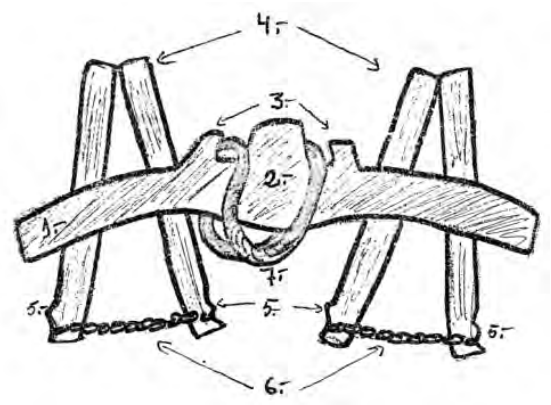

Fig. 1. Xugo (Vilariño 1972)

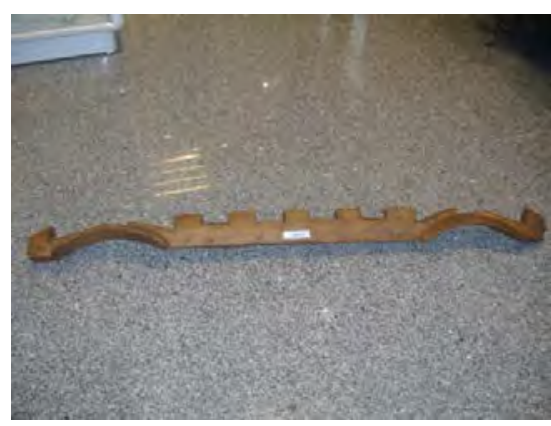

Fig. 2. Xugo (Araújo et al. 2006)

En canto á datación das obras galegas, exceptuando dúas que están datadas en 1938 e 1949, o resto sitúanse cronoloxicamente entre 1967 e 2012, concentrándose a maioría delas na década dos 70. Gran parte do léxico que se recolle nestas obras está vinculado á agricultura, á gandería, aos oficios tradicionais e a outros ámbitos da vida cotiá, ao ser humano (partes do corpo e prácticas sociais), ao ámbito doméstico ou ao tempo meteorolóxico.

\section{A TRADICIÓN LEXICOGRÁFICA GALEGA}

A lexicografía galega arrinca a mediados do século XIX coa obra Diccionario gallego-castellano de F. J. Rodríguez, editado postumamente en 1863 (González Seoane 2003: 166). Aínda que desde o primeiro terzo do século XVI se rexistraron algunhas tentativas de compilación de materiais léxicos en galego que seguían unha ordenación alfabética máis ou menos perfecta (González 
CAStro, O. / M. LiÑEIRA (eds.) (2015): Trama e urda. Contribucións multidisciplinares desde os estudos galegos, Santiago de Compostela, Consello da Cultura Galega. doi:10.17075/tucmeg.2015.

Seoane 2014: 167-168), a situación social, cultural e política do galego provocou que ata o século XVIII non aparecesen os primeiros estudos sobre o seu léxico da man dos precursores: Frei Martín Sarmiento e o Padre Sobreira. Sarmiento traballou na elaboración de dúas obras que non tiñan formato clásico de dicionario: o Catálogo de voces y frases de la lengua gallega e o Catálogo de voces vulgares y en especial de voces gallegas de diferentes vegetales, que non viron a luz ata o século XX. Os materiais que estas obras recollen serviron de fonte para os dicionarios galegos que se publicarían posteriormente, coma o Diccionario gallego elaborado por X. Cuveiro Piñol en 1876, no que amplía a información con voces medievais e do galego occidental. Con todo, a obra lexicográfica máis importante do século XIX foi o Diccionario gallegocastellano de Marcial Valladares, que depurou as voces que tomou dos dicionarios anteriores e incluíu exemplos tirados de obras literarias de autores da época (Rosalía de Castro, Vicente Turnes, Alberto Camino, etc.) e tamén de cantigas populares ou refráns. Este foi o dicionario galego de referencia durante décadas ata a publicación póstuma dunha das obras monumentais da lexicografía galega, o Diccionario enciclopédico gallego-castellano de Eladio Rodríguez (1958-1961), que comprendía tres volumes e que incorporaba voces xa incluídas nos dicionarios precedentes. Esta obra incorporaba tamén moitas palabras novas e información de tipo etnográfico. En 1968 publicouse o Dicionario galego-castelán de X. L. Franco Grande, outro dos históricos dicionarios galegos, que foi editado oito veces, xa que era un dicionario de pequeno formato que vía reducido o número de entradas. En palabras de González Seoane

El diccionario de Franco Grande es una especie de versión abreviada del diccionario de Eladio, del que se eliminan los lemas y acepciones coincidentes con el español, así como la información enciclopédica y paremiológica, al tiempo que se simplifican y reducen las definiciones. Pero por otra parte, el autor completa los registros del diccionario de Eladio con materiales de cosecha propia, de modo que el resultado final es, en cuanto al número de entradas, bastante parejo. (González Seoane 2014: 172)

Ata este momento a nosa tradición lexicográfica caracterízase por ser basicamente acumulativa e por un transvasamento de información de dicionario a dicionario. Podemos falar de achegas de léxico tirado de textos literarios e do coñecemento directo dos lexicógrafos, pois son moi escasos os traballos de recollida sistemática de léxico do galego oral e dialectal. A partir de mediados dos anos 80, as editoriais galegas renovan a súa oferta lexicográfica para acomodala ás novas necesidades derivadas do proceso de codificación e normalización do galego. Na lexicografía máis recente, elaborada a partir dun maior coñecemento do galego oral e dialectal, a contribución de maior relevancia para o coñecemento do léxico dialectal é o Glosario de voces galegas 
CAStro, O. / M. LiÑEIRA (eds.) (2015): Trama e urda. Contribucións multidisciplinares desde os estudos galegos, Santiago de Compostela, Consello da Cultura Galega. doi:10.17075/tucmeg.2015.

de hoxe (1985), de Constantino García. Trátase dunha obra que compila un total de 45 glosarios ou vocabularios inéditos, elaborados como traballos académicos entre os anos 1968 e 1984 (memorias de licenciatura e teses dirixidas polo propio Constantino García no Departamento de Filoloxía Románica e no Instituto da Lingua Galega da Universidade de Santiago de Compostela). No entanto, a compilación máis importante e completa da lexicografía galega aparece no 2001 da man de Antón Santamarina: o Dicionario de Dicionarios (actualmente só dispoñible en rede). ${ }^{32}$ Esta ferramenta informática recolle un total de 32 traballos lexicográficos, entre eles o glosario de Constantino García mencionado. O Dicionario de Dicionarios contén a día de hoxe un total de 392.768 entradas, segundo os datos de xuño de 2011 que se poden consultar na propia obra.

A partir do conxunto de obras pioneiras elaboradas ata comezos do século XX vaise formando a historia da lexicografía galega tal e como a coñecemos hoxe e van aparecendo outros dicionarios con melloras, tanto cuantitativas coma cualitativas. Antón Santamarina (2001: 11-15) considera que poderiamos establecer dúas distincións no que respecta aos nosos dicionarios: por autor (dicionarios individuais e dicionarios de equipo) e pola lingua (dialectal ou literaria). Con todo, debemos ter en conta que aínda que, como afirma Santamarina, os nosos dicionarios fanse a partir de dúas achegas fundamentais (por un lado, os propios dicionarios precedentes mediante a agregación de novos materiais ao acervo construído colectivamente -esas achegas poden proceder das variedades dialectais coñecidas polo autor ou autores, ou non- e por outro, aqueles que se realizaron a partir da lingua escrita) falta unha base nas formas e acepcións da lingua popular. Isto pode deberse, en boa medida, a que non existiu unha recollida sistemática ata o derradeiro cuarto do século XX (fóra da tradición anterior); pero tamén a que os lexicógrafos carecían de instrumentos que lles facilitaran o acceso a esa información. Este problema vese remediado cun proxecto como é o Tesouro, no que teñen cabida todo tipo de obras lexicográficas, ofrecéndolle ademais á comunidade científica a súa distribución territorial mediante a cartografía dixital.

\subsection{Contribución do Tesouro á lexicografía galega}

O Tesouro contribúe a rexistrar e preservar o patrimonio léxico, tanto polo volume de información compilada coma pola diversidade das fontes, máis aínda tendo en conta que a desaparición dos modos de vida tradicionais leva canda si a extinción, se cadra definitiva, dunha parte significativa do noso patrimonio léxico. A pesar de que polo de agora as obras que compoñen a base de datos son

${ }^{32}$ Pódese consultar o $D d D$ no enderezo electrónico: http://sli.uvigo.es/ddd/index.html 
CAStro, O. / M. LiÑEIRA (eds.) (2015): Trama e urda. Contribucións multidisciplinares desde os estudos galegos, Santiago de Compostela, Consello da Cultura Galega. doi:10.17075/tucmeg.2015.

relativamente escasas, xa que esta aínda está en construción, malia recibir achegas continuadas de novos materiais, é posible comprobar xa a utilidade desta plataforma. A seguir mostraremos algúns exemplos que amosan o aproveitamento do Tesouro para a lexicografía galega, ao dar a coñecer aos usuarios, por unha banda, palabras que non aparecen recollidas en ningunha outra obra e, pola outra, palabras que si se rexistran nos dicionarios pero con outras acepcións.

\subsubsection{Palabras que non se rexistran en ningunha outra obra anterior}

O feito de que o Tesouro estea formado por obras inéditas ou por estudos que ata o de agora non eran de fácil acceso para a comunidade científica fai posible que este proxecto poña por primeira vez á disposición dos usuarios, conxuntamente, vocabulario que non aparecía recollido ata o momento en ningún outro dicionario. Vexamos algúns exemplos:

a) En González (2002), obra introducida no Tesouro, aparece recollido o termo rábade. A autora define a palabra como «comida de peces» e presenta un exemplo para ilustrar como se emprega o vocábulo en Cangas do Morrazo: «No viveiro dáslle rábade que é comida e o peix aghuanta muitos días». Nos dicionarios galegos consultados, o Dicionario da Real Academia Galega (de aquí en diante DRAG) e o Dicionario de Dicionarios (de aquí en diante $D d D$ ), a palabra rábade non se encontra rexistrada.

b) Pasemisí tamén aparece definido en González (2002) como «juego infantil». Con toda probabilidade refírese a un xogo moi popular ata hai algúns anos, que se practicaba mentres se cantaba a canción «Pase misí, pase misá, por la puerta de Alcalá, los de alante corren mucho, los de atrás se quedarán». A palabra pasemisí, que probablemente teña a súa orixe en Pase Monsieur, non aparece rexistrada nos dicionarios galegos consultados; aínda que a información que ofrece a autora e que aparece recollida no Tesouro sexa escasa, pode ser un punto de partida para posibles investigacións etnográficas específicas no campo dos xogos infantís.

c) Acarroular aparece definido por Rielo (1971) como «echar a rodar la carroula o cualquier objeto rodante». Esta entrada e a súa definición tampouco aparecen rexistradas en ningún dicionario galego, aínda que Aníbal Otero relacione acarroular con arrebullar «echar a rodar». Pero podemos relacionar acarroular coa palabra carroula (xunto coa variante carrula), que tamén aparece recollida no Tesouro en Rielo (1971) e que define como «rueda de madera y raras veces de piedra para entretenimiento de niños. Se la hace rodar cuesta abajo». O nome deste obxecto que se usa nos xogos infantís aparece recollido no $D d D$ en Eligio Rivas (2001), que o define como «Juego del aro y el mismo aro o rueda», e polo tanto o Tesouro, coa información que nos fornece, ofrécenos outros datos e amplíanos coñecementos acerca deste pasatempo que cómpre ter en conta se desexamos investigar o campo dos xogos infantís, como comentabamos no exemplo anterior. 
CAStro, O. / M. LiÑEIRA (eds.) (2015): Trama e urda. Contribucións multidisciplinares desde os estudos galegos, Santiago de Compostela, Consello da Cultura Galega. doi:10.17075/tucmeg.2015.

d) Arreleixar, cuxa acepción é «tocar a morto», aparece recollida por Castro (1986) no Corgo. Este termo, relacionado co campo temático da morte, dáse a coñecer por primeira vez ao público desde esta plataforma, xa que ata o de agora só se rexistraba na tese de licenciatura de Castro, polo que non era de fácil acceso para a comunidade investigadora. Con todo, podemos relacionalo coa entrada tocan a releixo, que se recolle en Reguera y Pardiñas (1840-1858) no $D d D$ e que define como «Hay difunto, quiere decir. Se usa en Sarria, Castroverde y casi en la mayor parte de la provincia de Lugo. Proviene de relegar o dejar el mundo». En dicionarios máis tardíos rexístrase a forma releixo, que aparece no $D d D$ no apéndice ao dicionario de Eladio Rodríguez (1961) e tamén en Franco Grande (1972), onde se define como «toque de difuntos».

A través dos exemplos que acabamos de observar, podemos comprobar que este proxecto contribúe á recuperación de voces que, de apareceren recollidas unicamente nunha tese de licenciatura ou en calquera outro traballo lexicográfico, probablemente quedarían no esquecemento por diversos motivos (escaso número de exemplares, dificultade de acceso, etc). O Tesouro é unha plataforma que lle outorga visibilidade a materiais deste tipo, ademais de permitir unha consulta fácil e rápida dende calquera lugar e de ofrecernos a localización exacta dos materiais a través dun mapa dixital, máis aló de mencionarnos simplemente o lugar no que se recolleron os datos.

\subsubsection{Palabras que se rexistran en dicionarios, pero con outras acepcións}

A heteroxeneidade das obras que compoñen o Tesouro tamén contribúe ao enriquecemento da lexicografía galega, xa que atopamos numerosas voces que, aínda que foron recollidas en dicionarios, no Tesouro aparecen con significados diferentes non antes rexistrados.

a) Oveiro aparece recollido en obras coma o $D R A G$ co significado de «persoa que compra e vende ovos»; o $D d D$, pola súa parte, rexístrao co significado de «ovario de las aves» nos dicionarios de Carré Alvarellos (1928-1931; 1933; 1951 e 1979), Ibáñez Hernández (1950), Eladio Rodríguez (1958-1961) e Franco Grande (1972). Cabe destacar que dentro do Tesouro só se rexistra en Leis (1969) co significado de «el que se mete en cosas de mujeres»; e deste xeito vemos como este recurso nos permite engadir unha acepción máis a esta palabra.

b) Morriñento rexístrase no Tesouro (Leis 1969) co significado de «tacaño». Na maioría dos dicionarios, por exemplo no $D R A G$, rexístrase con varias acepcións: (1) «que ten suciedade, roña»; (2) «que sente tristeza, melancolía, que ten poucos ánimos e incluso é débil fisicamente»; «que produce tristeza, cansazo etc». Os significados relacionados coa nostalxia son os que se rexistran tamén no $D d D$ en Carré Alvarellos (1928-1931; 1933; 1951; 1971), Ibáñez Fernández (1950), Eladio Rodríguez (1958-1961) ou Franco Grande (1972). Pola contra, coa acepción de «tacaño» non se recolle en ningún dos glosarios consultados, polo que vemos que de novo o Tesouro permite documentar unha acepción 
CAstro, O. / M. LiÑEIRA (eds.) (2015): Trama e urda. Contribucións multidisciplinares desde os estudos galegos, Santiago de Compostela, Consello da Cultura Galega. doi:10.17075/tucmeg.2015.

que os textos lexicográficos existentes non rexistran. Se reparamos en que a voz morriñento asume un significado metafórico de «tacaño» de xeito análogo a outras palabras da súa mesma esfera semántica como son cotroso, cotrento, cotrenoso e roñoso, podemos ampliar as buscas establecendo unha comparación que nos permita examinar logo os resultados obtidos do Tesouro e dos dicionarios galegos. Aínda que cotroso no Tesouro só se rexistra co significado de «sucio» en Acosta (1970) e Gil (1969), este significado aparece recollido no $D R A G$ e no $D d D$ xunto co de «que aforra en exceso, que gasta ou dá o menos posible». Pola contra, si que se rexistran esas dúas acepcións baixo a entrada cotrento no Tesouro: «tacaño» en Porto do Son rexistrada por Marín (1978), e «mugriento, roñoso, sucio» en Cangas, recollida por González GM (2002). A variante cotrenoso, polo de agora, só se rexistra no Tesouro en Redondela, nun estudo léxico de Monteagudo (1998), co significado de «aforrica, cutre, misquiño, ser coma a Virgen do puño, roñoso, tacaño». Deste xeito, ao establecer unha relación entre esas tres formas e comprobar que nin cotrenoso nin cotrento se rexistran no $D R A G$, e no $D d D$ só Constantino García (1985) indica que cotrento é variante de cotroso, vemos que o Tesouro ofrece información adicional de novo, ofrecéndonos máis datos e información lexicográfica. Algo semellante ocorre coa entrada roñoso, xa que esta palabra si aparece recollida no Tesouro en Redondela (Monteagudo 1998) co significado de «pouco espléndido, que non lle gusta comparti-las súas cousas. Sinónimo de aforrica, agharrado, cotrenoso, cutre, misquiño e tacaño». En cambio esta forma xa non aparece recollida no $D R A G$, e no $D d D$ só figura en Constantino García (1985) co significado de «tacaño», no Grove, polo que de novo este exemplo permítenos reafirmar que este recurso é unha ferramenta particularmente valiosa para enriquecer a lexicografía galega.

Nos exemplos que acabamos de mostrar podemos comprobar que o Tesouro ofrece a posibilidade de consultar palabras xa coñecidas, en moitos casos próximas a calquera usuario da lingua galega, pero cun significado particular que descoñeciamos ata o momento. Deste xeito, este proxecto contribúe a non perder acepcións que só eran coñecidas polos membros dunha comunidade lingüística concreta e que, a través desta plataforma, poderán chegar a todos os usuarios.

Por último, hai outro tipo de termos que no Tesouro están no mesmo nivel que as demais entradas, mentres que nos dicionarios aparecen nun lugar secundario baixo as entradas principais. O feito de que nesta ferramenta aparezan estas formas introducidas así tamén facilita a súa busca e polo tanto tamén o seu coñecemento e estudo. É o caso dos lemas complexos ou locucións coma cabalo do demo, que no Tesouro acadan unha maior visibilidade.

c) Cabalo do demo aparece lematizado no Tesouro coma cabalo do demo e clasificado como «locución substantiva masculina» (loc sm). Deste xeito recibe o tratamento doutra entrada calquera e sitúase tamén a un primeiro nivel. Pola contra, o habitual en practicamente todos os dicionarios, coma neste caso o $D R A G$, é que as locucións coma cabalo do demo aparezan nun segundo nivel, isto é, baixo a entrada principal cabalo. En 
CAstro, O. / M. LiÑEIRA (eds.) (2015): Trama e urda. Contribucións multidisciplinares desde os estudos galegos, Santiago de Compostela, Consello da Cultura Galega. doi:10.17075/tucmeg.2015.

canto á definición, nesta mesma obra defínese este termo como «insecto da suborde dos anisópteros coa cabeza e o tórax unidos, ollos moi desenvolvidos, abdome longo e fino e dous pares de ás que vive preto da auga e do que existen varias especies» e como sinónimos aparecen os termos cabaliño do demo e libélula. Se introducimos a expresión cabalo do demo no Tesouro, debido á variedade de obras que hai xa introducidas na base de datos, atopamos 21 entradas procedentes cada unha delas de diferentes obras: Baamonde (1977), Couceiro (1967), Díaz (1971), Fraga (1968), Fraíz (1974), González (2002), Leis (1969), Marín (1978), Morandeira (1969), Palacio (1974), Pena (1970), Pérez (1969), Pérez F. (1972), Prado (1971), Rodríguez (1971), Sánchez (1971), Santamarina (1967), Seco (1971), Vázquez (1971), Vázquez F (1971) e Vilariño (1972). Das 21 entradas rexistradas, 20 ofrecen a mesma definición de cabalo do demo: «libélula», mentres que unha delas (González 2002) define cabalo do demo como «mantis relighiosa», o que nos permite reflexionar sobre a fiabilidade dos datos que nos proporcionan as diversas fontes ao non coincidiren as definicións, como ocorre neste caso. A medida que vaia aumentando o número de obras introducidas, maior seguridade poderemos ter sobre a información introducida ao ser posible a comparación de máis resultados. Con todo, ademais desta información que nos ofrece o Tesouro e que complementa e amplía a que podemos atopar nos dicionarios, cabe destacar que este proxecto sobresae polo feito de mostrar moita máis fraseoloxía e significados asociados que é común nos dicionarios. Por exemplo, para a palabra cabalo o DRAG presenta as frases e expresións: a cabalo, a cabalo de, cabalo de batalla, cabalo de mar, cabalo do demo, cabalo de vapor e a locución de a cabalo. A estas formas podemos engadir outras que si atopamos no Tesouro: cabalo de parada, cabalo de posto, cabalo do demo, cabalo rabañés, sopas de cabalo cansado, renda do cabalo etc.

En definitiva, o Tesouro é unha ferramenta indispensable para poder conservar o noso patrimonio léxico que se ve ameazado polo desuso co abandono do mundo rural tradicional e dos seus modos de vida. Aínda que este é un risco ao que están expostas incluso linguas que gozan dun recoñecemento e dun prestixio nas súas sociedades como é o inglés, francés, español e portugués, esta perigosa situación agrávase no caso do galego, que está vivindo en situacións de extrema dificultade e que por esta razón precisa con urxencia de proxectos e iniciativas que permitan preservar o seu patrimonio lingüístico e cultural.

\section{A DIALECTOLOXÍA GALEGA}

O léxico dialectal tamén recibirá importantes achegas coa información xeolingüística que facilita o Tesouro. $\mathrm{O}$ estudo deste léxico principia no 
CAStro, O. / M. LiÑEIRA (eds.) (2015): Trama e urda. Contribucións multidisciplinares desde os estudos galegos, Santiago de Compostela, Consello da Cultura Galega. doi:10.17075/tucmeg.2015.

primeiro cuarto do século XX, cando Fritz Krüger e outros investigadores alemáns coma Schroeder e Schneider inician os estudos dialectais no dominio galego (Regueira 1996: 52-53). Non obstante, unha das obras de incalculable valor desde o punto de vista dialectolóxico é o Atlas Lingüístico de la Península Ibérica, cuxos materiais recolle na súa meirande parte Aníbal Otero, axudado nalgunhas localidades por Aurelio Espinosa, entre 1934 e 1935 en 53 puntos espallados polo territorio galego. Nalgúns deles a recollida de datos completaríase entre 1953 e 1954 por quedar estancados os traballos debido á guerra civil española (Sousa 2009: 304). O cuestionario do ALPI estaba dividido en dúas seccións: Caderno I (fonética, morfoloxía e sintaxe) cun total de 411 preguntas e Caderno IIE (léxico) con 833 preguntas, aínda que as formas recollidas eran arredor de 2.000 .

Desde a guerra civil a dialectoloxía quedou desatendida, pero na década dos sesenta comezan a aparecer numerosos traballos dialectolóxicos (memorias de licenciatura, teses de doutoramento, etc) da man de lingüistas formados na Universidade de Santiago de Compostela e preocupados pola lingua galega.

Pouco despois, en 1974 iníciase o proxecto clave no desenvolvemento da xeografía lingüística galega: o Atlas Lingüístico Galego ( $A L G a)$. Os cuestionarios do $A L G a$ están formados por un total de 2.711 preguntas que se realizaron in situ en 167 puntos distribuídos de xeito homoxéneo por todo o territorio galego (García / Santamarina 1990: 10-11). O promedio de formas recollidas en cada cuestionario era dunhas 4.000. A fonética, morfoloxía e sintaxe ocupan da pregunta 1 ata a 527, mentres que o léxico, agrupado tematicamente, vai dende a 527 ata a 2.711. A pesar de que o número de preguntas era moi amplo, prescindiuse do léxico mariñeiro xa que había un total de vinte e cinco localidades costeiras galegas exploradas para o Atlas Lingüístico de los Marineros Peninsulares. A diversidade de obras que dende a xeolingüística se ocupan de estudar o galego e a envergadura dalgunhas delas contribúen a que teñamos na actualidade un bo coñecemento da variación dialectal da nosa lingua.

\subsection{Contribución do Tesouro á dialectoloxía galega}

Son moitos e moi diferentes os traballos existentes no galego que ofrecen información lexicográfica con referencia xeográfica e que integrarán o Tesouro. Isto permitiralle a este proxecto concentrar todo un corpus que terá unha maior visibilidade e un acceso máis doado para toda a comunidade científica. En poucos anos fíxose en Galicia un grande esforzo por conseguir monografías que levantasen os datos lingüísticos de pequenos territorios, un concello na maior parte dos casos. Son obras descritivas 
CAStro, O. / M. LiÑEIRA (eds.) (2015): Trama e urda. Contribucións multidisciplinares desde os estudos galegos, Santiago de Compostela, Consello da Cultura Galega. doi:10.17075/tucmeg.2015.

indispensables para o estudo dialectolóxico que ao integralas nunha mesma base de datos como é o Tesouro, ao relacionalas e poder comparalas, permítennos ver en que medida se repiten as formas e significados e que difusión territorial teñen. Aínda botando man do escaso número de obras coas que conta o Tesouro polo de agora, podemos verificar que é posible tirar proveito desta plataforma para levar a cabo estudos dialectolóxicos ao ofrecernos dúas posibilidades:

a) Incremento do volume e da complexidade de información recollida.

Dada a multitude e a variedade de obras que integran este proxecto, a información contida e ofrecida é moito maior que a que poida ofrecer calquera tipo de obra existente ata o momento na dialectoloxía galega, pois todas elas formarán parte desta iniciativa. Así mesmo, a rede de puntos onde se rexistran as investigacións lingüísticas tamén será maior pois, ademais das enquisas cubertas en diversos puntos a través dos atlas lingüísticos, recolleuse moita máis información en distintos lugares ao elaborarse as monografías dialectais, ás veces coincidindo coas redes dos atlas ou completándoas, de modo que o universo de informantes tamén é maior, e outras veces son novas localidades que enriquecen os datos existentes. No que respecta aos informantes, cabe reparar en que o atlas busca un informante típico como modelo (García / Santamarina 1990: 11) mentres que as monografías dialectais preguntan a unha comunidade de falantes, ou o que é o mesmo, un grupo amplo e representativo da localidade en cuestión.

b) Posibilidade de estudos diacrónicos.

O elevado número de obras que albergará o Tesouro ofrecerá grandes vantaxes en canto aos estudos diacrónicos, no momento no que este proxecto conte cun número considerable de obras. Ao compartir información procedente de estudos de distintas épocas dun xeito tan completo, permitiralle á comunidade científica unha explotación dos datos para posibles estudos de variación ou cambio lingüístico no tempo, podendo contrastar os materiais dos anos 30 (procedentes do Atlas Lingüístico de la Península Ibérica), os dos anos 70 (obtidos a partir das enquisas realizadas para o Atlas Lingüistico Galego) e os dunha ampla variedade de datas correspondentes á multitude de estudos que están sendo incorporados ao Tesouro pertencentes a diferentes períodos, polo de agora comprendidos entre 1938 e 2012. Deste xeito o Tesouro permitirá comprobar a vixencia de determinadas solucións, a emerxencia dunhas e o declive doutras, e axudará a encher algunhas lagoas ou a precisar e matizar a distribución dalgunhas formas. 
CAStro, O. / M. LiÑEIRA (eds.) (2015): Trama e urda. Contribucións multidisciplinares desde os estudos galegos, Santiago de Compostela, Consello da Cultura Galega. doi:10.17075/tucmeg.2015.

\section{CABO}

Como puidemos comprobar ao longo destas páxinas, a contribución do Tesouro do léxico patrimonial galego portugués é de grande utilidade para a lexicografía e dialectoloxía galegas. O Tesouro constitúe unha achega ao coñecemento e á recuperación dun importante número de voces que talvez quedarían relegadas ao esquecemento de non existir unha plataforma dixital coma esta, que funcione como galería para o aproveitamento de infinidade de materiais lexicográficos e dialectais. A consulta de toda a información será doada, gratuíta e de acceso universal. A heteroxeneidade de obras que compoñen este proxecto tamén incrementa o valor deste corpus, xa que permite realizar consultas nun amplísimo conxunto de textos, aínda que sempre respectando a singularidade de cada un deles.

As posibilidades de busca van máis alá das típicas dos dicionarios convencionais, pois tamén se poden realizar outros tipos de busca, por exemplo por campo semántico, ou recompilar toda a información precisa sobre unha voz determinada ou consultar os refraneiros contidos en determinadas obras ou outro tipo de datos. Os usuarios desta plataforma dixital teñen á súa disposición moita información dun valor incalculable, tanto desde o punto de vista lexicográfico coma dialectal. Ademais, o aproveitamento que podemos facer do Tesouro non é estritamente lingüístico, senón que constitúe tamén un corpus útil para outras disciplinas coma a antropoloxía, a botánica e a historia. En definitiva, é unha ferramenta imprescindible, pois o descoñecemento do noso léxico é sinónimo do descoñecemento da nosa cultura, do que foi o noso modo de vida, e polo tanto, de nós mesmos.

\section{REFERENCIAS BIBLIOGRÁFICAS}

ACOSTA GARCÍA, María Teresa de (1970): El habla de Piedrafita, memoria de Licenciatura, Universidade de Santiago de Compostela.

ÁLVAREZ BLANCO, R. et alii (2009): «Presentación de un corpus digital de léxico tradicional: El Tesouro do léxico patrimonial galego e portugués», Fonetică şi Dialectologie, XXVIII, 5-19.

ÁlVAREZ PÉREZ, X. A. / Xulio C. SOUSA FERNÁNDEZ (2013): «The Tesouro do Léxico Patrimonial Galego e Portugués. A Galician and Portuguese Word Bank», Dialectologia, Special issue, IV, 5-24.

$A L G a=$ C. GARCÍA / A. SANTAMARINA (dirs.) (1990-): Atlas Lingüístico Galego, A Coruña, Fundación Pedro Barrié de la Maza / Instituto da Lingua Galega, vols. I-V.

ARAÚJO GARCÍA, Teresa / Pablo CARBALLO FELPETE / María Isabel GIL CACHEIRO / Consuelo LOSADA RODRÍGUEZ / María Dolores PARDO VÁZQUEZ (2006):

Vilariño de Conso: paisaxe e tradición, Ourense, Deputación Provincial. 
CAStro, O. / M. LIÑEIRA (eds.) (2015): Trama e urda. Contribucións multidisciplinares desde os estudos galegos, Santiago de Compostela, Consello da Cultura Galega. doi:10.17075/tucmeg.2015.

BAAMONDE TRAVESO, Gloria (1977): A fala das parroquias de Arante e Cedofeita, memoria de licenciatura, Universidade de Santiago de Compostela.

CASTRO CASTEDO, Xosé Manuel (1986): O galego en Queizán (O Corgo, memoria de licenciatura, Universidade de Santiago de Compostela.

COUCEIRO PÉREZ, José Luis (1967): Vocabulario de Feás, memoria de licenciatura, Universidade de Santiago de Compostela.

DdD = A. SANTAMARINA (ed.) (2003): Diccionario de diccionarios, Versión 3, A Coruña, Fundación Pedro Barrié de la Maza / Instituto da Lingua Galega.

DÍAZ CARNERO, Mercedes (1971): El léxico de Castrocaldelas, memoria de licenciatura, Universidade de Santiago de Compostela.

DRAG = C. GARCÍA / M. GONZÁLEZ GONZÁLEZ (dirs.): Diccionario da Real Academia Galega, A Coruña, RAG / Xerais / Galaxia.

FRAGA GARCÍA, Ramón (1968): Vocabulario de Mellid y cercanías, memoria de licenciatura, Universidade de Santiago de Compostela.

FRAIZA BARREIRO, María de los Ángeles (1974): El léxico de Codeseda, memoria de licenciatura, Universidade de Santiago de Compostela.

GIL SUÁREZ, María del Carmen (1969): El habla de Villardevós, memoria de licenciatura, Universidade de Santiago de Compostela.

GONZÁLEZ GONZÁLEZ, Margarita (2002): El gallego hablado de Cangas de Morrazo, tese de doutoramento, Universidad de Oviedo.

GONZÁLEZ SEOANE, E. (2003): «A lexicografía galega moderna», en Henrique Monteagudo / Xan Bouzada (coords.), O proceso de normalización do idioma galego 1980-2000. V. III, Santiago de Compostela, Consello da Cultura Galega, 165 - 228.

LEIS CASANOVA, Inés (1969): El habla de Santa Eulalia de Dumbría, memoria de licenciatura, Universidade de Santiago de Compostela.

LÓPEZ TABOADA, Carme (1978): El habla de la comarca de Sobrado de los Monjes, memoria de licenciatura, Universidade de Santiago de Compostela.

MARÍN SUÁREZ, María de los Ángeles (1978): O lésico de San Sadurniño de Joianes, memoria de licenciatura, Universidad de Valladolid.

MONTEAGUDO CABALEIRO, María Teresa (1998): Contribución ó estudio do léxico do concello de Redondela, memoria de licenciatura, Universidade de Santiago de Compostela.

MORANDEIRA LOURÉS, Josefa (1969): El habla de Lage, memoria de licenciatura, Universidade de Santiago de Compostela.

NAVARRO TOMÁS, T. (1962): Atlas Lingüistico de la Península Ibérica, Volume I. Fonética, Madrid, CSIC.

PALACIO SÁNCHEZ, José Antonio (1974): Notas sobre el léxico de Ferreira de Pantón (Lugo), memoria de licenciatura, Universidade de Santiago de Compostela.

PENA SEIJAS, Xesús (1970): Vida e fala de Guitiriz (Negradas), memoria de licenciatura, Universidade de Santiago de Compostela.

PÉREZ ALONSO, María Jesús (1969): Vocabulario de Goián, memoria de licenciatura, Universidade de Santiago de Compostela.

PÉREZ FROIZ, María Inés (1972): El léxico de Santa María de Oirós, memoria de licenciatura, Universidade de Santiago de Compostela. 
CAStro, O. / M. LiÑEIRA (eds.) (2015): Trama e urda. Contribucións multidisciplinares desde os estudos galegos, Santiago de Compostela, Consello da Cultura Galega. doi:10.17075/tucmeg.2015.

PRADO FERNÁNDEZ, Margarita (1971): Vocabulario de Ferreira del Valle de Oro, memoria de licenciatura, Universidade de Santiago de Compostela.

RIELO CARBALLO, Nicanor (1971): «Vocabulario gallego de Arcos de Frades», Compostellanum XVI/1-4 [= II Congreso Internacional de Estudios Jacobeos], 303-332.

RODRÍGUEZ GANDOY, Eladio (1971): El léxico del ayuntamiento de Guntín (Lugo), memoria de licenciatura, Universidade de Santiago de Compostela.

SÁNCHEZ SÁNCHEZ, Aurora (1971): El léxico de Montederramo, memoria de licenciatura, Universidade de Santiago de Compostela.

SANTAMARINA FERNÁNDEZ, Antón (1967): Vocabulario del Valle de Suarna, memoria de licenciatura, Universidade de Santiago de Compostela [integrado en Id. (1973): El habla del Valle de Suarna. 2 vols., tese de doutoramento, Universidade de Santiago de Compostela].

SANTAMARINA FERNÁNDEZ, A. (2001): «Os lexicógrafos galegos, historia dunha profesión», en Eladio Rodríguez González, Día das letras galegas 2001, Santiago de Compostela, Universidade de Santiago de Compostela.

SECO FERNÁNDEZ, Ramón (1971): El léxico de Santa Comba, memoria de licenciatura, Universidade de Santiago de Compostela.

SOUSA FERNÁNDEZ, X. C. (2009): «Notas sobre o Atlas Lingüístico de la Península Ibérica en Galicia», en Mercedes BREA / Francisco FERNÁNDEZ REI / Xosé Luís REGUEIRA (eds.), Cada palabra pesaba, cada palabra medía. Homenaxe a Antón Santamarina, Santiago de Compostela, Universidade de Santiago de Compostela, 299-306.

TLPGP $/$ Tesouro = ÁLVAREZ BLANCO, Rosario (coord.): Tesouro do léxico patrimonial galego e portugués, Santiago de Compostela, Instituto da Lingua Galega. (http://ilg.usc.es/Tesouro)

VÁZQUEZ FERNÁNDEZ, María Isabel (1971): El habla y léxico de San Julián de Pereiramá (Lugo), memoria de licenciatura, Universidade de Santiago de Compostela. VÁZQUEZ SANTAMARÍA, María Ester (1971): El habla de La Gudiña, memoria de licenciatura, Universidade de Santiago de Compostela.

VILARIÑO SECO, Josefina (1972): El léxico de San Braulio de Caaveiro, memoria de licenciatura, Universidade de Santiago de Compostela. 